\title{
ALONSO, MANUEL; AMBROSINI, CRISTINA; BERALDI, GASTÓN. Bestiario epistemológico. Metáforas zoomórficas y de otras entidades en la enseñanza de las ciencias y la epistemología. Buenos Aires, Editorial de la Facultad de Fi- losofía y Letras de la UBA, 2017.
}

El pensamiento nos acostumbra al juego de las oposiciones: desde los griegos, al mito se opone el logos, la episteme (ciencia) se diferencia claramente de la doxa (opinión) y el conocimiento de la fantasía. En este juego opositivo, a la ciencia le corresponde el polo de un saber mejor fundamentado que el resto de los saberes y, en la versión positivista, un tipo de conocimiento fundamentado racionalmente, objetivo e imparcial. En el otro polo, la literatura es el terreno de la fantasía, de la imaginación, de la exploración sobre otros mundos posibles que, siendo ficticios, son visionarios y anticipan, en algunas oportunidades, lo que luego ocurrirá.

En este Bestiario, que presentan tres profesores del Ciclo Básico Común de la Universidad de Buenos Aires, la oposición, la tensión y el antagonismo son el leitmotiv de este zoológico. Debemos recordar que el Ciclo Básico Común de la Universidad de Buenos Aires, creado en 1985, intentó desde su inicio, ser un "espacio democrático de cambio e innovación pedagógica basado en una enseñanza básica, común y transdisciplinaria”, bajo la convicción de que el encuentro entre disciplinas, en un espacio común de formación académica, se puede enriquecer el trabajo de los docentes en beneficio de los futuros profesionales y científicos. Con esto se espera que la interdisciplina ocurra en el inicio y no en el final de una carrera disciplinar.

Este Bestiario compila parte de la tarea inter-cátedras que se lleva a cabo entre las materias Biología e Introducción al Pensamiento Científico y es el resultado de una línea de investigación sostenida a lo largo de estos últimos años donde convergen la epistemología, la ética, la biología y la enseńanza en ciencias naturales. Estos recursos metafóricos están orientados, según nos dicen los autores, a mostrar al conocimiento científico como una construcción a través de la elaboración de teorías y modelos históricamente situados con sus implicancias sociales y bioéticas.

Como señala desde el Prólogo el Dr. Héctor Palma, uno de los principales referentes de la valoración cognitiva de las metáforas científicas en nuestros medios académicos, durante siglos se ha considerado a las ciencias como el ejemplo más acabado y pleno de un lenguaje referencialmente preciso, formalizado, y como el resultado de procedimientos algorítmicos claramente pautados y controlados; y del otro lado a la literatura o al discurso retórico, como el campo de la asociación libre, la falta de límites lógicos y formales, de la mera intuición y creatividad sin rigurosidad racional, apelando a todo tipo de artimañas semánticas, incluidas las metáforas. Tender puentes entre estas dos esferas separadas y antagónicas del discurso es también una de las intenciones de los autores. Para ello recurren a otras metáforas, el puente y la muralla, tomadas de la obra del Dr. Ricardo Maliandi, donde se muestra el antagonismo entre el cambio y la permanencia, entre la conquista del futuro frente a la necesidad de preservar el pasado, lo ya conquistado. La aplicación de esta tensión en el campo de las metáforas para tipificar los conceptos epistemológicos, indica que estos recursos pueden ser transitados como puentes, para propiciar nuevos significados, o pueden ser vistos como obstáculos en el sentido de 


\section{8/ Perspectivas Metodológicas /19/Vol. II /Año 2017}

"obstáculos epistemológicos" ya explorados por Gastón Bachelard. Otra polaridad que atraviesa el Bestiario es la que puede ubicarse entre lo animal y lo humano asociados a la polaridad, a su vez, entre lo racional y lo irracional. Otra oposición que recorre y da sentido a esta revisión de metáforas es, la ya señalada en la obra de Thomas Kuhn, entre la revolución y la normalidad; entre la ruptura y la continuidad.

El libro se divide en dos partes. En la Parte I los autores recorren sus marcos teóricos, sus autores de referencia en la valoración de las metáforas como figuras que pueden tener un valor cognitivo en el lenguaje científico. Aquí se admite que las metáforas no son solamente formas subsidiarias de un lenguaje que luego debe ser "traducido" a otro lenguaje original, neutro y transparente, sino que ellas tienen un valor epistémico, y son constitutivas en la producción de conocimiento que realizan los científicos y luego apropian los estudiantes. En apoyo a esta idea se señala básicamente el aporte de Héctor Palma en cuanto a la valoración positiva de las metáforas científicas pero también se recurre a Paul Ricoeur.

En cuanto a la noción de "tensión" y "agonismo" se recurre en varios pasajes a Miguel de Unamuno. En la Parte II se presentan los animales en pares antagónicos, donde se pueden encontrar: La abeja lógica vs. La mosca estética como símbolos que señalan dos actitudes: el seguimiento estricto de los procedimientos deductivos frente a la actitud de entregarse al azar y la improvisación como nota vital que logra superar así los obstáculos en los que queda prisionera la abeja lógica. El par de animales antagónicos que se presentan luego de estos dos insectos epistemológicos son: El pavo inductivista, habitante de los Manuales de epistemología en los que se formaron generaciones de científicos y El cisne negro, presentado por Nassim Niklas Taleb, el filósofo libanés que representa en esta rara avis la actitud refutacionista de Karl Popper que, en oposición al inductivista quien confía en la constancia y regularidad de los acontecimientos, espera siempre la irrupción de lo altamente improbable, que se prepara para reorientar su investigación y romper las reglas transitadas hasta el momento. El pato-conejo, instalado en la epistemología a partir de los años 30' del Siglo XX, representa la ambigüedad siempre presente en las interpretaciones del mundo. Como dice Kuhn, lo que antes de la revolución eran patos, serán conejos después. En este sentido representa el pato-conejo la contrafigura de El gallo del positivismo, que se niega a admitir otra realidad que la de los "hechos" y en nombre de la objetividad y la imparcialidad se entroniza como verdad consagrada. El camello y El león riente son símbolos tomados de los animales de Nietzsche, que representan también personajes antagónicos donde el primero es obediente y carga con los pesos, transita el desierto, mientras el segundo representa la actitud del espíritu libre, todavía reactivo a los valores consagrados, todavía incompleto en su transformación hacia la ingenuidad del creador pero ya habitante de un mundo donde la risa es posible para confrontar con lo consagrado también como "serio". En paralelo con estas dos figuras nietzscheanas, El gato de Cheschire junto al Conejo Blanco tomados de Lewis Carroll parece simbolizar de este modo la actitud irónica y burlona del gato frente a las reglas impuestas por la Reina de Corazones. El Conejo Blanco, como contratara, representa la actitud servil y sumisa frente al poder imperante y el acatamiento a las reglas. El ornitorrinco es aludido por Umberto Eco para señalar los límites de todo sistema clasificatorio en su libro Kant y el ornitorrinco. Este símbolo muestra los límites de los sistemas clasificatorios y con ello los límites de nuestro lenguaje para inventar categorías universales. 
El gatopardo inverso nos da la nota característica de los procesos revolucionarios: la preocupación por mostrarse en continuidad con el paradigma hegemónico cuando está provocando su ruptura. Otras entidades como el humo del progreso, el árbol de la vida y el fantasma teleológico muestran la vigencia del positivismo y del creacionismo aún después de la revolución darwiniana.

Como nos dicen los autores, este Bestiario fue motivado, en solidaridad con la tradición iniciada por Esopo y La Fontaine para "aprender" algo de los animales y sacar alguna moraleja. También en solidaridad con otras obras geniales como Los viajes de Gulliver, Alicia en el país de las maravillas o el Zarathustra de Nietzsche, donde las caracterizaciones zoomórficas expresan el discurso de la racionalidad en el límite entre una animalidad humana y no humana, para tomar en broma la moralina que esconden las fábulas tradicionales.

El recurso a estas figuras resulta pertinente frente a un público de estudiantes nóveles, que no está totalmente en condiciones de acceder al tema propuesto de un modo puramente conceptual. La mediación de estos "animales" no pretende allanar las distancias entre los modelos científicos y la "supuesta" realidad que representarían sino que constituyen un modo más de hacer el intento de comprender la producción científico-tecnológica.

Como se dijo ya en el inicio, una de las actitudes destacadas en el libro es la de "tender puentes". La publicación del mismo libro es el resultado de esta actitud ya que la Facultad de Filosofía y Letras de la UBA es la editora de este libro que sirve de material de estudio para los estudiantes del Ciclo Básico Común de la UBA. Un rasgo de solidaridad y colaboración que merece ser destacado. También podemos advertir, en favor de la presentación de este Bestiario, la conveniencia de concebirnos como "animales" que más allá de la capacidad racional, tenemos compromisos de solidaridad y respeto con el resto de los seres vivos, con los que formamos una comunidad en tanto habitantes de un único y frágil planeta. 